\title{
Exposure to Adverse Events and Associations with Stress Levels and the Practice of Yoga: Survey Findings from a Population-Based Study of Diverse Emerging Young Adults
}

\author{
Dianne Neumark-Sztainer, $\mathrm{PhD}, \mathrm{MPH}, \mathrm{RD},{ }^{1}$ Melanie M. Wall, $\mathrm{PhD}^{2}$ Jongwoo Choi, $\mathrm{MS}{ }^{3}$ \\ Daheia J. Barr-Anderson, $\mathrm{PhD}^{4}$ Susan Telke, MS, and Susan M. Mason, $\mathrm{PhD}^{1}$
}

\begin{abstract}
Objectives: This study examines the prevalence of exposure to adverse events and associations with stress levels among a diverse population-based sample of young people. The study further explores whether these vulnerable populations, who have the potential to benefit from the mind-body practice of yoga, engage in a regular yoga practice.

Design: EAT 2018 (Eating and Activity over Time) is a population-based study in which survey data were collected from 1568 ethnically/racially diverse (81.2\% nonwhite) emerging young adults (mean age: $22.0 \pm 2.0$ years).

Results: Exposure to adverse events was highly prevalent. For example, $43.9 \%$ reported at least one adverse childhood experience (ACE) (e.g., physical, emotional, or sexual abuse before age 18), whereas $40.1 \%$ reported experiencing discrimination. Exposure to adverse events was associated with higher stress levels. Practicing yoga at least $30 \mathrm{~min} /$ week was reported by $12.7 \%$ of the population, with variation across sociodemographic characteristics. Young adults exposed to adverse events were either more or similarly likely to practice yoga than young adults not reporting adverse events.

Conclusions: The high prevalence of exposure to adverse events and associations with higher levels of stress points to a need for public health interventions. Thus, it was promising to find that young people exposed to adverse events, who may have greater emotional burdens, practice yoga at equal or greater proportions to those without these exposures. Given the potential benefits of yoga for populations living with high stress, it is important to develop further outreach efforts and provide accessible, acceptable, and affordable opportunities for practicing yoga.
\end{abstract}

Keywords: yoga, stress, adverse events, discrimination, diversity, young adults

\section{Introduction}

A DVERSE EXPERIENCES SUCH as childhood abuse, victimization, discrimination, and financial stress are highly prevalent social determinants of health. Individuals with histories of childhood abuse are at greater risk for suicide attempts, ${ }^{1}$ substance use, ${ }^{1}$ higher weight status, ${ }^{2}$ and cardiovascular disease. ${ }^{1,3}$ Racial discrimination and other stressful life events have likewise been linked to poor health outcomes, including mental health disorders and cardiovascular disease..$^{4-7}$ A key mechanism by which adversities across the life course may influence health is through

\footnotetext{
${ }^{1}$ Division of Epidemiology and Community Health, School of Public Health, University of Minnesota, Minneapolis, MN, USA.

${ }^{2}$ Department of Biostatistics, Mailman School of Public Health, Columbia University, New York City, NY, USA.

${ }^{3}$ Department of Statistics, Columbia University, New York City, NY, USA.

${ }^{4}$ School of Kinesiology, University of Minnesota, Minneapolis, MN, USA.

(C) Dianne Neumark-Sztainer et al. 2020; Published by Mary Ann Liebert, Inc. This Open Access article is distributed under the terms of the Creative Commons License (http:/ / creativecommons.org/licenses/by/4.0), which permits unrestricted use, distribution, and reproduction in any medium, provided the original work is properly cited.
} 
heightened stress, which can provoke both behavioral adaptations, such as use of drugs and alcohol to soothe distress, and cause direct physiologic maladaptation through wear and tear of organ systems involved in the stress response. ${ }^{8,9}$ Given the potential long-term impacts of exposure to adverse experiences, it is critical to ensure that individuals exposed to these experiences can access strategies for modulating their stress levels.

Yoga is a mind-body practice that involves physical postures, breathwork, mindfulness, and meditation. ${ }^{10-14}$ Through linking meditative breath to movement, yoga may lead to calming of the mind, decreased reactivity to challenging situations, and better stress management. ${ }^{15-17}$ Several scientific reviews conclude that yoga may have benefits in terms of reducing stress. ${ }^{18-21}$ Thus, the practice of yoga may be helpful for populations exposed to adverse events if they have opportunities for engaging in yoga and choose to do so. Yoga is becoming increasingly popular in the United States. ${ }^{1,22-24}$ Practicing yoga over the past year was reported by $9.5 \%$ of adults in 2012 and increased to $14.3 \%$ in $2017 .^{25}$

Despite the growing popularity of yoga, it is not clear if the practice is reaching those who might most benefit from it. The practice of yoga, with its potential to reduce stress and improve overall health, may be most needed by populations facing challenging situations, such as exposure to adverse life events. However, populations with limited financial resources may be most burdened by adverse life events, and some studies suggest that low-income populations are also less likely to practice yoga than those at higher income levels. ${ }^{22,26}$ However, the authors are unaware of any population-based studies that have examined the prevalence of practicing yoga among ethnically and socioeconomically diverse young adults who have been exposed to adverse life events.

This study examines the prevalence of exposure to adverse events in a diverse population of young people and associations with reported levels of stress. This study further examines whether young people from diverse backgrounds, and those exposed to adverse events are engaging in the practice of yoga. Specific research questions to be addressed are as follows: (1) What is the prevalence of exposure to adverse events, including adverse childhood experiences (ACEs), other stressful life events, discrimination, and financial struggles in a diverse population-based sample of adolescents and emerging young adults? (2) Do young people exposed to these adverse events have higher stress levels? (3) What is the prevalence of practicing yoga in young people across sociodemographic characteristics and among those exposed to adverse and stressful experiences? (4) How is yoga cross-sectionally related to stress levels in the overall population and in those exposed to adverse events? Findings have implications for improving the health of vulnerable populations in general, and more specifically, can inform outreach and teaching within community-based settings in which yoga is taught.

\section{Materials and Methods}

\section{Study design and population}

EAT 2018 (Eating and Activity over Time) is an observational epidemiologic study examining eating, activity, and weight-related health and associated factors, in a population-based sample of young people. EAT 2018 is a follow-up survey to an earlier baseline study conducted in the academic year 2009-2010 (EAT 2010). At baseline participants were middle school and senior high school students at 20 urban public schools in Minneapolis-St. Paul, Minnesota who completed classroom surveys and anthropometric measures. ${ }^{27-29}$ EAT 2018 followed up 8 years later through online or mailed paper surveys. This study includes cross-sectional survey data collected in the year 2017-2018 from 1568 emerging young adults (age range: 18-26; mean age $=22.0 \pm 2.0$ years). The University of Minnesota's Institutional Review Board Human Subjects Committee approved all protocols.

The 1568 young people who completed surveys at both assessments represents $65.8 \%$ of the original participants for whom current contact information was available at EAT 2018. Inverse probability weighting (IPW) was used for all analyses to account for missing data. ${ }^{30,31}$ IPW minimizes potential response bias due to missing data and allows for extrapolation back to the original EAT 2010 school-based sample. Weights for IPW were derived as the inverse of the estimated probability that an individual responded at the two time points based on characteristics reported in 2010, including demographics, past year frequency of dieting, and weight status. Demographic characteristics of the weighted sample included in the current analysis are shown in Table 1.

\section{Survey development and variables}

Key items from the EAT 2010 survey were included on the follow-up EAT 2018 survey. ${ }^{3,27,32}$ Additions to the survey were also made to assess areas of emerging interest

Table 1. Sociodemographic Characteristics of Study Population $(N=1568$; Weighted Percentages)

\begin{tabular}{lcr}
\hline & $\mathrm{n}$ & $\%$ \\
\hline Age (years), mean (SD) & & \\
Age categories & $22.1(2.0)$ & \\
18-21 & 712 & 42.7 \\
$22-25$ & 802 & 53.1 \\
$26-30$ & 54 & 4.1 \\
Gender & & \\
Male & 649 & 46.3 \\
Female & 908 & 53.1 \\
Different identity & 11 & 0.6 \\
Ethicity/race & & \\
White & 366 & 18.8 \\
Black & 345 & 29.0 \\
Hispanic & 274 & 19.9 \\
Asian & 355 & 3.7 \\
Native American & 63 & 11.8 \\
Other/mixed & 165 & \\
Socioeconomic status & & 39.4 \\
Low & 565 & 17.9 \\
Low-middle & 334 & 7.5 \\
Middle & 257 & \\
High-middle & 241 & \\
High & 134 & \\
\end{tabular}


and to reflect participants' transition from adolescence to young adulthood. To inform survey development, three focus groups $(n=29)$ were conducted in which participants first completed the EAT 2018 survey and were asked to provide input on survey content and data collection strategies. The final survey was then fielded and test-retest reliability of measures was examined using data from a subgroup of 112 participants who were asked to complete the EAT 2018 survey twice within a period of 3 weeks.

Variables used in this study include exposure to adverse events in childhood (ACEs), over the lifetime (stressful life events), or currently occurring (discrimination, and current financial struggles); past-month stress level, yoga practice, and sociodemographic characteristics. Variables, including survey questions, psychometric properties, and sources, are described in Table 2.

\section{Statistical analysis}

Descriptive proportions of each adverse event are reported across the whole sample. Separate linear regressions were used to estimate the association between each dichotomous adverse event as the predictor of stress, yielding mean stress levels for those exposed and not exposed to each experience. Both crude (unadjusted) models and models controlling for age, gender, ethnicity/race, and socioeconomic status (SES) (adjusted models) were run. The proportion of individuals practicing yoga across different sociodemographic groups and by the presence of each adverse event was examined by regressing yoga practice (yes/no) on each adverse event and sociodemographic characteristics in separate logistic models. Regressionadjusted proportions of individuals practicing yoga by each adverse event were obtained by back-transforming the logit at the conditional mean of the covariates (age, gender, ethnicity/race, and SES). Finally, the authors examined associations between yoga and stress. The sample size differed slightly across analyses due to intermittent missingness of items. Item missingness ranged from $1.0 \%$ to $3.9 \%$. As previously described, to adjust for attrition, all regression analyses and percentages were weighted with the nonresponse weights (IPW) while raw sample size values are presented. All analyses were conducted in SAS software (version 9.4, 2013; SAS, Inc., Cary, NC).

\section{Results}

\section{Prevalence of exposure to adverse events}

At least one ACE (physical, emotional, sexual abuse, or household dysfunction before the age of 18) was reported by $45.1 \%(n=696)$ of the study participants. One-third $(33.2 \%$; $n=500$ ) of participants reported at least one stressful life event, such as being the direct victim of violence or having a close friend or family member die violently. Experiencing discrimination at least a few times a year, such as being treated with less respect than other people, was reported by $40.1 \%(n=614)$ of the participants. Finally, 23.2\% $(n=337)$ reported that it was either very difficult or extremely difficult to manage financially. Correlations between the different experiences ranged from 0.17 (between ACEs and financial struggles) to 0.31 (between ACEs and stressful life events).

\section{Stress levels by exposure to adverse events}

The overall mean stress level in the sample was 5.9 (standard deviation $=2.6$; scale range: $1-10$ ). Perceived stress levels were significantly higher among young people exposed to adverse events (i.e., ACEs, stressful life events, discrimination, or financial struggles) than among those not exposed. The effect size in standardized mean differences of stress ranged from moderate ( 0.43 standard deviations) for stressful life events to large (0.74 standard deviations) for financial struggles. Associations were statistically significant ( $p<0.001$ for all comparisons) in unadjusted analyses and in analyses adjusted for age, gender, ethnicity/race, and SES (Table 3).

Stressful life events explained $3.8 \%$ of the variance in perceived stress level in the unadjusted model and $8.4 \%$ of variance after adjusting for sociodemographic characteristics. Discrimination explained $7.4 \%$ of the variance in stress level in the unadjusted model and $11.7 \%$ of the variance after adjustment. ACEs explained $9.2 \%$ of the variance in perceived stress level in the unadjusted model and $13.0 \%$ of variance in stress, after adjustment for sociodemographic characteristics. Financial struggles explained $8.9 \%$ of variance in stress level in the unadjusted model and $13.8 \%$ of the variance in stress level in the adjusted model.

\section{Prevalence of yoga practice}

Approximately one-fifth $(n=335 ; 19.9 \%)$ of participants reported ever having practiced yoga over the past year. Among those who reported ever practicing yoga $(n=335)$, the average frequency of practicing yoga each week over the past year was $<30 \mathrm{~min} /$ week $(n=123 ; 35.7 \%) ; 30 \mathrm{~min}$ to $<1 \mathrm{~h} /$ week $(n=68 ; 20.5 \%) ; 1 \mathrm{~h}$ to $<2 \mathrm{~h} /$ week $(n=84 ; 25.7 \%)$; $2+\mathrm{h} /$ week $(n=58 ; 17.5 \%)$. For all additional analyses, only those practicing for an average of at least $30 \mathrm{~min} /$ week over the past year ( $n=210 ; 12.7 \%$ of the total study population) were coded as practicing yoga.

Table 4 shows the prevalence of practicing yoga at least $30 \mathrm{~min} /$ week in the entire study population by sociodemographic characteristics. Yoga practice did not differ across age. Large differences were seen across gender; $7.2 \%$ of young men, $17.2 \%$ of young women, and $36.4 \%$ of those with a different gender identity practiced yoga $(p<0.001)$. Prevalences were fairly similar between white $(14.6 \%)$, black (11.1\%), Hispanic (12.4\%), and Asian (10.6\%) participants, whereas prevalences were lower among Native Americans (7.0\%) and highest among those from mixed/ other backgrounds (19.4\%). Yoga was practiced across all levels of SES, with the highest levels among those from the highest socioeconomic level (19.2\% at highest level vs. $10.7 \%$ at lowest level).

\section{Yoga practice by exposure to adverse events}

Young adults exposed to adverse events were as or more likely to practice yoga than young adults not reporting adverse events (Table 5). In unadjusted analyses, yoga was practiced by $16.2 \%$ of young adults exposed to adverse childhood events as compared with $10.0 \%$ of those not exposed $(p<0.001)$, with similar findings after adjustment for sociodemographic characteristics. Likewise, $14.8 \%$ of those exposed to stressful life events practiced yoga as compared 
Table 2. Variables Assessed in Study and Description of Survey Items

\begin{tabular}{|c|c|}
\hline Variables & Description of survey items \\
\hline ACEs & $\begin{array}{l}\text { Adverse experiences in childhood ( }<18 \text { years) were assessed by asking participants about their } \\
\text { own experiences of physical, emotional, and sexual abuse as well as three questions regarding } \\
\text { other dimensions of dysfunction in their childhood household. The authors defined } \\
\text { participants as exposed to each type of maltreatment using the following definitions, informed } \\
\text { by the ACEs Scale. } 99,50 \text { Physical abuse: ever being hit by a family member so hard that it left } \\
\text { bruises or marks. Emotional abuse: an adult in the family saying hurtful or insulting things } \\
\text { "often" or "very often." Sexual abuse: ever experienced unwanted sexual touching or forced } \\
\text { sex from an adult in one's family and/or from an adult outside one's family. Participants were } \\
\text { also asked to answer three questions (yes/no) regarding whether a household member was } \\
\text { "a problem drinker or alcoholic, used street drugs, or abused prescription drugs"; was } \\
\text { "depressed, mentally ill, or attempted suicide"; or "went to prison." An indicator variable } \\
\text { was defined to represent none or at least one adverse experience (test-retest } \\
\text { agreement = 85\%). }\end{array}$ \\
\hline Stressful life events & $\begin{array}{l}\text { Participants indicated whether or not they had experienced the following six events: "had } \\
\text { problems with the police"; "been hit, shoved, held down or had some other physical force } \\
\text { used against you by a spouse or someone you were dating"; "been forced to touch a dating } \\
\text { partner or spouse sexually or had some type of sexual behavior forced on you"; "been } \\
\text { attacked, beaten, or mugged (not including events that involved a parent, caretaker, teacher, } \\
\text { spouse, or dating partner)"; "had a close family member or friend die violently"; and } \\
\text { "witnessed a situation in which someone was seriously injured or killed, or in which you } \\
\text { feared someone would be seriously injured or killed." Survey items were based on the Life } \\
\text { Events Questionnaire, }{ }^{2} \text { Brief Trauma Questionnaire, }{ }^{52} \text { and previous Project EAT surveys. } \\
\text { A dichotomous variable was created to represent having experienced any of the six events at } \\
\text { any point (test-retest agreement }=85 \% \text { ). }\end{array}$ \\
\hline Discrimination & $\begin{array}{l}\text { Participants were asked how often they experience three forms of interpersonal discrimination: (1) } \\
\text { "You are treated with less respect or courtesy than other people," (2) "You receive poorer } \\
\text { service than other people in restaurants and stores," and (3) "People act as if they think you are } \\
\text { not smart or clever." Items were selected from tools that have been used to assess the impact of } \\
\text { stigma and discrimination in longitudinal studies. "Response options for each item were } \\
\text { "Never," "Less than once a year," "A few times a year," "A few times a month," and "At } \\
\text { least once a week." Frequency responses for the three forms of discrimination were summed } \\
\text { with a range of scores from } 3 \text { to } 15 \text { (Cronbach's } \alpha=0.83 \text {, } \\
\text { test-retest } r=0.69 \text { ) and then dichotomized at } 7 \text { corresponding to these three types of } \\
\text { discrimination happening on average at least a few times a year. }\end{array}$ \\
\hline Financial situation & $\begin{array}{l}\text { "How difficult is it for you to get by financially right now?", }{ }^{-58} \text { Response options included } \\
\text { "Not at all difficult," "Somewhat difficult," "Very difficult or can barely get by," and } \\
\text { "Extremely difficult or impossible" (test-retest } r=0.72 \text { ). Responses were dichotomized such } \\
\text { that only responses indicating very difficult or extremely difficult challenges were taken to } \\
\text { represent financial struggles (test-retest agreement }=92 \% \text { ). }\end{array}$ \\
\hline Yoga practice & $\begin{array}{l}\text { Young adults indicated if they had ever done yoga over the past year (yes/no) (test-retest } \\
\text { agreement }=89 \% \text { ). Those who had ever done yoga were additionally asked, "On average, } \\
\text { how frequently did you do yoga over the past year?" Seven response options ranged from } \\
\text { "less than } 1 / 2 \text { hour/week" to "10+ hours/week." Respondents who engaged in yoga at least } \\
30 \mathrm{~min} / \text { week were identified as practicing yoga (test-retest agreement }=86 \% \text { ). }\end{array}$ \\
\hline Perceived stress & $\begin{array}{l}\text { "On a scale from one to ten, with one being not stressed at all and ten being very stressed, how } \\
\text { would you rate your average level of stress in the past } 30 \text { days?" (test-retest } r=0.69 \text { ). This } \\
\text { measure of stress was previously developed for a similar population of young adults. }\end{array}$ \\
\hline $\begin{array}{l}\text { Sociodemographic } \\
\text { characteristics }\end{array}$ & $\begin{array}{l}\text { Sociodemographic variables included age (based on date of birth), ethnicity/race, SES, and } \\
\text { gender. Ethnicity/race was assessed at baseline with the question: "Do you think of yourself } \\
\text { as...? (1) White, (2) Black or African American, (3) Hispanic or Latino, (4) Asian American, } \\
\text { (5) Native Hawaiian or Pacific Islander, (6) American Indian or Native American, or (7) } \\
\text { Other"' (test-retest agreement }=98 \%-100 \%) \text {. Since very few participants reported "Hawaiian, } \\
\text { or Pacific Islander," or did not report their ethnicity/race, they were coded as "mixed/other." } \\
\text { Categorization of SES was determined at baseline and was primarily based on the highest } \\
\text { education level of either parent with adjustments made for student eligibility for free/reduced- } \\
\text { price school meals, family public assistance receipt, and parent employment status. } 60,61 \\
\text { On the EAT } 2018 \text { survey, participants were given three options for gender: male, female, } \\
\text { or different identity (please specify). There were } n=11(0.6 \%) \text { who responded "Different } \\
\text { identity" and } n=15(0.9 \%) \text { who did not respond. Nonresponders were recoded with their } \\
\text { gender identity (male or female) from EAT } 2010 \text {. All others were coded with their gender } \\
\text { as reported in EAT } 2018 \text {. }\end{array}$ \\
\hline
\end{tabular}

All items were assessed on the EAT 2018 survey unless indicated otherwise.

ACE, adverse childhood experience. 
Table 3. Distribution of Exposure to Adverse Events and Associated Stress Levels

\begin{tabular}{|c|c|c|c|c|c|c|c|c|}
\hline & \multirow[b]{2}{*}{$\mathrm{n}$} & \multirow[b]{2}{*}{$\begin{array}{l}\text { \% Experiencing } \\
\text { adverse event }\end{array}$} & \multicolumn{3}{|c|}{ Unadjusted results } & \multicolumn{3}{|c|}{ Adjusted results ${ }^{\mathrm{a}}$} \\
\hline & & & $\begin{array}{c}\text { Stress } \\
\text { (mean level) }\end{array}$ & $S E$ & $\mathrm{p}$ & $\begin{array}{c}\text { Stress } \\
\text { (mean level) }\end{array}$ & $S E$ & $\mathrm{p}$ \\
\hline \multicolumn{9}{|l|}{ ACEs } \\
\hline Yes & 696 & 45.1 & 6.8 & 0.09 & \multirow[t]{2}{*}{$<0.001$} & 6.8 & 0.10 & \multirow[t]{2}{*}{$<0.001$} \\
\hline No & 834 & 54.9 & 5.2 & 0.10 & & 5.2 & 0.09 & \\
\hline \multicolumn{9}{|l|}{ Stressful life events } \\
\hline Yes & 500 & 33.2 & 6.6 & 0.12 & \multirow[t]{2}{*}{$<0.001$} & 6.7 & 0.12 & \multirow[t]{2}{*}{$<0.001$} \\
\hline No & 1031 & 66.8 & 5.5 & 0.09 & & 5.6 & 0.09 & \\
\hline \multicolumn{9}{|l|}{ Discrimination } \\
\hline High & 614 & 40.1 & 6.8 & 0.10 & \multirow[t]{2}{*}{$<0.001$} & 6.8 & 0.10 & \multirow[t]{2}{*}{$<0.001$} \\
\hline Low & 909 & 59.9 & 5.3 & 0.09 & & 5.4 & 0.09 & \\
\hline \multicolumn{9}{|l|}{ Financial struggles } \\
\hline Very or extremely difficult & 337 & 23.2 & 7.3 & 0.13 & \multirow[t]{2}{*}{$<0.001$} & 7.4 & 0.13 & \multirow[t]{2}{*}{$<0.001$} \\
\hline somewhat or not difficult & 1176 & 76.8 & 5.5 & 0.08 & & 5.5 & 0.08 & \\
\hline
\end{tabular}

${ }^{a}$ Adjusted for age, gender, ethnicity/race, and SES.

SES, socioeconomic status.

with $11.7 \%$ of those not exposed to stressful life events, although this difference was not statistically significant $(p=0.060)$. Discrimination and financial hardship were unrelated to prevalence of yoga practice.

\section{Perceived stress by yoga practice}

In the overall population, perceived stress was higher $(p<0.001)$ among young adults practicing yoga $($ mean $=$ 6.6) than those not practicing yoga (mean=5.8) in unadjusted analyses, although the effect size was small $(0.29$ standardized difference). In analyses adjusting for sociode- mographic characteristics, perceived stress levels remained higher for those practicing yoga $(p=0.014)$, but the effect size was reduced to a 0.19 standardized mean difference. Among young adults exposed to each adverse event, perceived stress level did not differ by yoga practice in unadjusted analyses or in analyses adjusted for sociodemographic characteristics (Table 6).

\section{Discussion}

Findings indicate a high prevalence of exposure to adverse events among an urban population-based sample of

Table 4. Yoga Practice (At Least 30 Min/Week) by Sociodemographic Characteristics

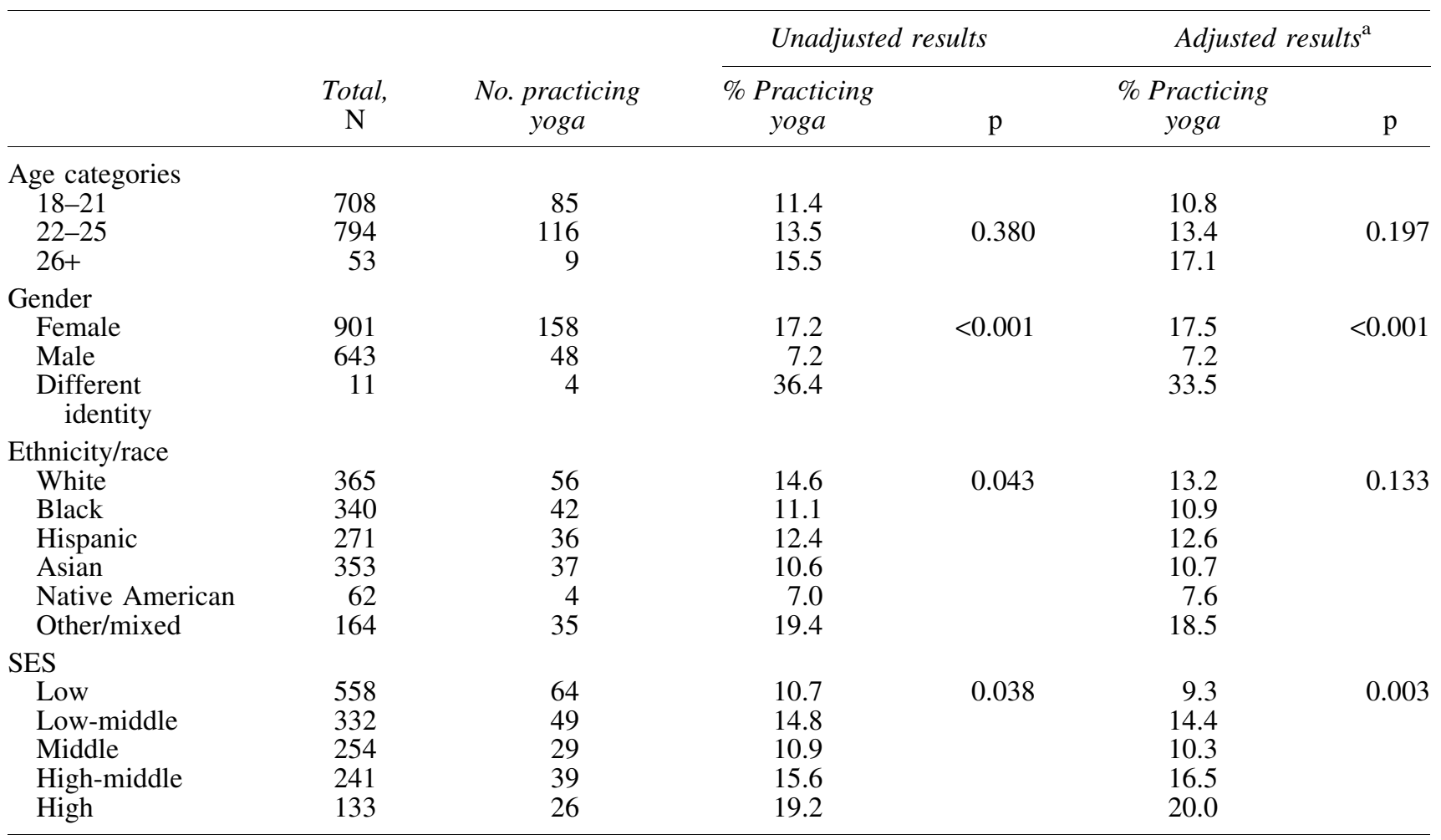

\footnotetext{
${ }^{\mathrm{a}}$ Adjusted for age, gender, ethnicity/race, and SES.
} 
Table 5. Yoga Practice by Exposure to Adverse Events

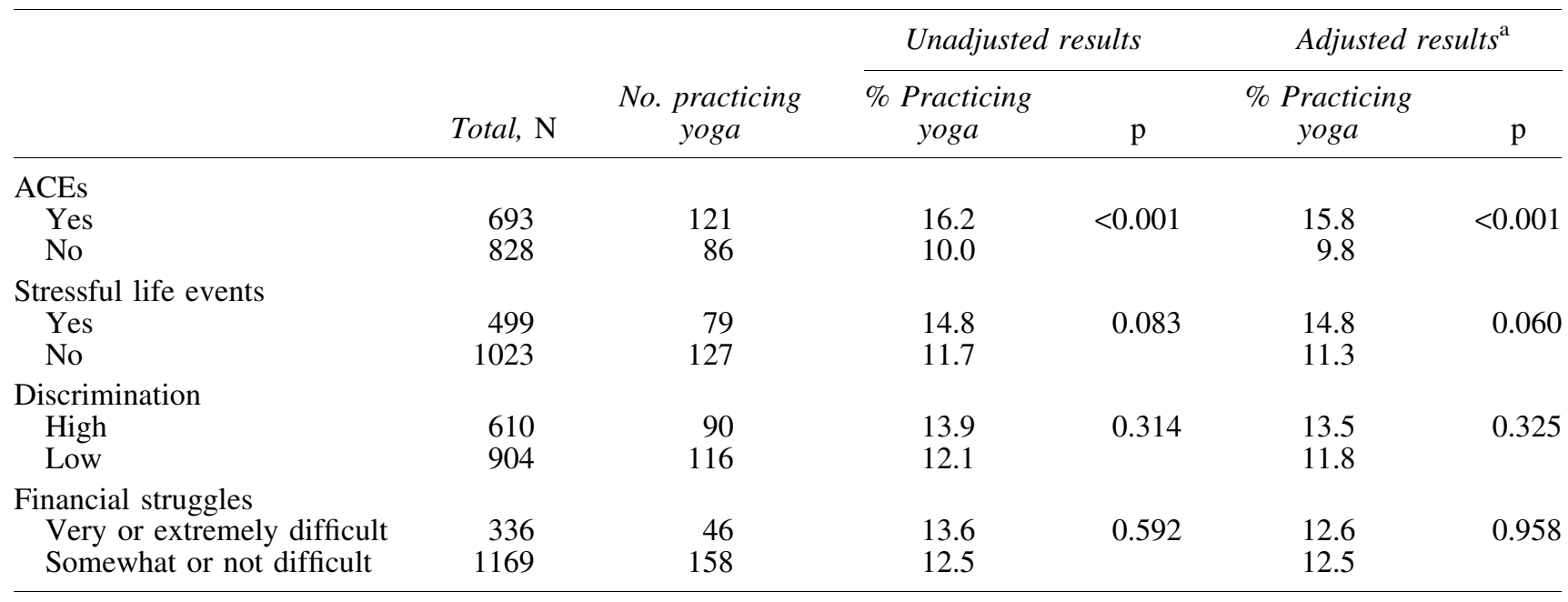

${ }^{a}$ Adjusted for age, gender, ethnicity/race, and SES.

diverse young people. Furthermore, young people exposed to these adverse events reported higher levels of stress than their counterparts. Findings further indicate that young people exposed to adverse events practice yoga at equal or greater proportions to other young people without these exposures. Finally, perceived stress was positively associated with yoga practice in the overall population but did not differ across yoga practice among young people exposed to adverse events. Findings suggest the importance of ensuring that yoga teachers recognize that many of the students in their classes may have been exposed to potentially traumatic situations.

The high prevalence of reported exposures to adverse events is disturbing, inexcusable, and preventable. For example, $40 \%$ of young people reported adverse childhood events and $40 \%$ reported concerning levels of discrimination. Unfortunately, the high prevalences are not unique to the current study population. The original ACEs study, conducted among Kaiser Permanente members, found that $\sim 50 \%$ of the sample had experienced one or more ACEs. ${ }^{33}$ Likewise, $60 \%$ of respondents to the Behavioral Risk Factor Surveillance survey, a nationally representative sample, reported at least one ACE. ${ }^{34}$ The lower $40 \%$ prevalence in the current sample may be due to the more limited number of adversities measured (e.g., parental divorce was not included).

Not surprisingly, and similar to other studies, ${ }^{35}$ young people exposed to each of these adverse events had significantly higher perceived stress levels than their counterparts.
The effect size in standardized mean differences of stress ranged from moderate for stressful events to large for financial struggles. Furthermore, analyses indicated that exposure to adverse events explained a high percentage of variance in perceived stress levels, particularly exposure to ACEs and current financial struggles. Higher levels of perceived stress have been shown to be associated with poorer health outcomes of major public health importance. ${ }^{36-38}$

Yoga was practiced by a high percentage of emerging young adults in this diverse population-based sample. Yoga was more likely to be practiced by young women than young men, which is consistent with the literature. ${ }^{22,25}$ In this study, young people from different ethnic/racial and socioeconomic backgrounds practiced yoga at relatively similar percentages. Differences across sociodemographic characteristics were less apparent than in other studies, 22,25 suggesting either a unique aspect of this sample, or that among younger people, yoga is becoming more available, acceptable, and/or accessible to varied groups.

Given the growing recognition of the potential benefits of yoga for physical and emotional well-being, ${ }^{17,39-42}$ it was promising to see that young people who reported adverse events (i.e., ACEs, discrimination, stressful life events, and financial struggles) practiced yoga at least as often as their counterparts. Close to half $(44 \%)$ of the participants reported ACEs and yoga was practiced by higher percentages of young people reporting ACEs than their peers $(16 \%$ vs. $10 \%)$. Importantly, these findings indicate that

Table 6. Stress Levels by Yoga Practice in Young People Exposed to Traumatic Situations

\begin{tabular}{|c|c|c|c|c|c|c|}
\hline & \multicolumn{3}{|c|}{ Unadjusted results } & \multicolumn{3}{|c|}{ Adjusted results ${ }^{\mathrm{a}}$} \\
\hline & \multicolumn{2}{|c|}{ Mean stress levels (SE) } & \multirow[b]{2}{*}{$\mathrm{p}$} & \multicolumn{2}{|c|}{ Mean stress levels (SE) } & \multirow[b]{2}{*}{$\mathrm{p}$} \\
\hline & Practice yoga & No yoga & & Practice yoga & No yoga & \\
\hline ACEs $(n=693)$ & $7.0(0.21)$ & $6.7(0.10)$ & 0.336 & $6.8(0.22)$ & $6.8(0.10)$ & 0.843 \\
\hline Stressful life events $(n=276)$ & $6.8(0.31)$ & $6.6(0.12)$ & 0.433 & $6.7(0.32)$ & $6.7(0.12)$ & 0.916 \\
\hline Discrimination $(n=610)$ & $7.0(0.25)$ & $6.7(0.11)$ & 0.308 & $6.9(0.25)$ & $6.8(0.11)$ & 0.729 \\
\hline Financial struggles $(n=336)$ & $7.5(0.35)$ & $7.3(0.14)$ & 0.651 & $7.6(0.36)$ & $7.4(0.14)$ & 0.719 \\
\hline
\end{tabular}

${ }^{\text {a} A d j u s t e d ~ f o r ~ a g e, ~ g e n d e r, ~ e t h n i c i t y / r a c e, ~ a n d ~ S E S . ~}$ 
approximately half of the young people in this sample who practice yoga have been exposed to at least one ACE. Although further research is needed to determine if similar patterns exist in other populations, and to determine the effectiveness of yoga in helping these young people, the authors' findings suggest that populations exposed to adverse events are engaging in a practice that, if offered sensitively, has the potential to be of help through getting in touch with their bodies, reducing stress, and practicing self-compassion.

In the overall study population, young people practicing yoga reported higher levels of perceived stress than those not practicing yoga. Among young people exposed to adverse events, practicing yoga was not found to be associated with perceived stress. These findings are cross sectional, thus inferences about direction cannot be made. Given the overall tenets of yoga and existing research showing that yoga is beneficial for stress management, ${ }^{18-21}$ the authors do not believe that yoga is leading to increased stress. Another explanation is that yoga may increase one's awareness to internal signs of stress through the practice of coming inward and listening. Alternatively, young people living with more stress, and/or those aware of their internal stress levels, may seek out yoga as a practice to help. The lack of such difference in stress by yoga practice among those exposed to adverse events may indicate that the adverse events themselves, rather than perceived stress, are motivating yoga practice in these groups. Further research using longitudinal data and intervention designs are needed to assess the impact of practicing yoga on stress among populations exposed to adverse events. $39,43,44$

Study strengths and limitations should be considered in interpreting the findings. Study strengths include the large and diverse nature of the study population and the assessment of exposures to potentially traumatic events. Although yoga is often suggested as a strategy for helping individuals who have experienced trauma, the authors are unaware of any other population-based studies that have examined the practice of yoga among these vulnerable populations. Survey items on yoga practice and adverse events were only assessed at follow-up, and the cross-sectional nature of the data is a study limitation. Furthermore, questions were not asked about the context in which yoga was practiced (e.g., setting, type of yoga, and price). All measures were selfreported, and individuals may not perfectly recall adversities. The authors did not assess the specific time period for adversities. Self-reported stress has been found to be modestly correlated with objective stress measures, ${ }^{45}$ but also reflects individual variation in what is considered "normal" stress, and may not correspond directly to stress physiology. ${ }^{46}$ In addition, although utilizing a community-based sample is a study strength as it allows for a determination of who is practicing yoga, the mean frequency of practicing yoga tends to be low, with relatively few respondents reporting practicing an average of $>2 \mathrm{~h}$ a week. Finally, it is important to replicate these findings in other study populations as it is possible that yoga offered within the Minneapolis/St. Paul area is different (e.g., more available, affordable, and accessible) to that offered in other areas.

In conclusion, study findings demonstrate the high level of exposure to adverse events among young people and the associated higher levels of stress. From a public health perspective, it is imperative to address the needs of these young people. It is promising that young people from diverse ethnic/racial and socioeconomic backgrounds, in addition to subsectors of the population who had been exposed to adverse events, practice yoga. Given the potential benefits of the practice for populations living with high levels of stress, it is important to develop further outreach efforts to reach these populations and provide opportunities for practicing yoga to those who are interested that are accessible and affordable. Although yoga should certainly not be offered as a substitute for needed psychologic care, it is important for yoga teachers to know that many of their students have likely experienced adverse events in their lives and to teach in a manner that is sensitive to the needs of this population. $^{14,47,48}$

\section{Acknowledgments}

D.N.-S., the PRINCIPAL INVESTIGATOR of the study, conceptualized the article and wrote all drafts of the article. M.M.W. is a CO-INVESTIGATOR on the study and contributed to data analysis and interpretation of the data. J.C. conducted data analysis for this study. D.J.B.-A., S.T., and S.M.M. contributed to writing this article. All authors critically reviewed and approved the article and agree to be accountable for all aspects of the study regarding the accuracy or integrity of any part of the study.

\section{Disclaimer}

The content is solely the responsibility of the authors and does not necessarily represent the official views of the National Heart, Lung, and Blood Institute and the National Institutes of Health.

\section{Author Disclosure Statement}

No competing financial interests exist.

\section{Funding Information}

This study was supported by the National Heart, Lung, and Blood Institute through grant numbers R01HL127077 and R35HL139853.

\section{References}

1. Birdee GS, Legedza AT, Saper RB, et al. Characteristics of yoga users: Results of a national survey. J Gen Intern Med 2008;23:1653-1658.

2. Brugha TS, Cragg D. The list of threatening experiences: The reliability and validity of a brief life events questionnaire. Acta Psychiatr Scand 1990;82:77-81.

3. Bucchianeri MM, Eisenberg ME, Neumark-Sztainer D. Weightism, racism, classism, and sexism: Shared forms of harassment in adolescents. J Adolesc Health 2013;53: 47-53.

4. Adler NE, Rehkopf DH. U.S. disparities in health: Descriptions, causes, and mechanisms. Annu Rev Public Health 2008;29:235-252.

5. Williams DR. Stress and the mental health of populations of color: Advancing our understanding of race-related stressors. J Health Soc Behav 2018;59:466-485.

6. Wallace S, Nazroo J, Bécares L. Cumulative effect of racial discrimination on the mental health of ethnic minorities in 
the United Kingdom. Am J Public Health 2016;106:12941300.

7. Udo T, Grilo CM. Cardiovascular disease and perceived weight, racial, and gender discrimination in U.S. adults. J Psychosom Res 2017;100:83-88.

8. Kendall-Tackett KE. The Psychoneuroimmunology of Chronic Disease: Exploring the Links Between Inflammation, Stress, and Illness. Washington, D.C., USA, American Psychological Association, 2010.

9. Schneiderman N, Ironson G, Siegel SD. Stress and health: Psychological, behavioral, and biological determinants. Annu Rev Clin Psychol 2005;1:607-628.

10. Kraftsow G. Yoga for Transformation: Ancient Teachings and Holistic Practices for Healing Body, Mind, and Heart. New York: Penguin Compass, 2002.

11. Cook-Cottone CP. Mindfulness and Yoga for Self-Regulation: A Primer for Mental Health Professionals. New York: Springer Publishing Company, 2015.

12. Neumark-Sztainer D, Watts AW, Rydell S. Yoga and body image: How do young adults practicing yoga describe its impact on their body image? Body Image 2018; 27:156-168.

13. Watts AW, Rydell SA, Eisenberg ME, et al. Yoga's potential for promoting healthy eating and physical activity behaviors among young adults: A mixed-methods study. Int J Behav Nutr Phys Act 2018;15:42.

14. Piran N, Neumark-Sztainer D. Yoga and the experience of embodiment: A discussion of possible links. Eat Disord 2020:1-19. DOI:10.1080/10640266.2019.1701350

15. Riley KE, Park CL. How does yoga reduce stress? A systematic review of mechanisms of change and guide to future inquiry. Health Psychol Rev 2015;9:379-396.

16. Michalsen A, Grossman P, Acil A, et al. Rapid stress reduction and anxiolysis among distressed women as a consequence of a three-month intensive yoga program. Med Sci Monit 2005;11:CR555-CR561.

17. Bussing A, Michalsen A, Khalsa SB, et al. Effects of yoga on mental and physical health: A short summary of reviews. Evid Based Complement Alternat Med 2012;2012: 165410.

18. Pascoe MC, Bauer IE. A systematic review of randomised control trials on the effects of yoga on stress measures and mood. J Psychiatr Res 2015;68:270-282.

19. Sharma M. Yoga as an alternative and complementary approach for stress management: A systematic review. J Evid Based Complement Altern Med 2014;19:59-67.

20. Chong CS, Tsunaka M, Chan EP. Effects of yoga on stress management in healthy adults: A systematic review. Altern Ther Health Med 2011;17:32.

21. Pascoe MC, Thompson DR, Ski CF. Yoga, mindfulnessbased stress reduction and stress-related physiological measures: A meta-analysis. Psychoneuroendocrinology 2017;86:152-168.

22. Cramer H, Ward L, Steel A, et al. Prevalence, patterns, and predictors of yoga use: Results of a U.S. nationally representative survey. Am J Prev Med 2016;50:230-235.

23. Saper RB, Eisenberg DM, Davis RB, et al. Prevalence and patterns of adult yoga use in the United States: Results of a national survey. Altern Ther Health Med 2004;10: 44-49.

24. Peregoy J, Clarke T, Jones L, et al. Regional Variation in Use of Complementary Health Approaches by U.S. Adults. NCHS Data Brief, No. 146. Hyattsville, MD: National Center for Health Statistics, 2014.
25. Clarke TC, Barnes P, Black L, et al. Use of yoga, meditation, and chiropractors among U.S. adults aged 18 and over. NCHS Data Brief 2018;325:1-8.

26. Clarke TC, Black LI, Stussman BJ, et al. Trends in the use of complementary health approaches among adults: United States, 2002-2012. Natl Health Stat Rep 2015;79:1-16.

27. Larson N, Wall M, Story M, Neumark-Sztainer D. Home/ family, peer, school, and neighborhood correlates of obesity in adolescents. Obesity 2013;21:1858-1869.

28. Neumark-Sztainer D, Wall M, Larson N, et al. Secular trends in weight status and weight-related attitudes and behaviors in adolescents from 1999 to 2010. Prev Med 2012;54:77-81.

29. Arcan C, Larson N, Bauer K, et al. Dietary and weightrelated behaviors and body mass index among Hispanic, Hmong, Somali, and White adolescents. J Acad Nutr Diet 2014;114:375-383.

30. Little R. Survey nonresponse adjustments for estimates of means. Int Stat Rev 1986;54:139-157.

31. Seaman S, White I. Review of inverse probability weighting for dealing with missing data. Stat Methods Med Res 2011;22:278-295.

32. Neumark-Sztainer D, Wall M, Fulkerson JA, Larson N. Changes in the frequency of family meals from 1999 to 2010 in the homes of adolescents: Trends by sociodemographic characteristics. J Adolesc Health 2013;52:201206.

33. Felitti VJ, Anda RF, Nordenberg D, et al. Relationship of childhood abuse and household dysfunction to many of the leading causes of death in adults: The Adverse Childhood Experiences (ACE) study. Am J Prev Med 2019;56:774786.

34. Bynum L, Griffin T, Riding D, et al. Adverse childhood experiences reported by adults-five states, 2009. Morb Mortal Wkly Rep 2010;59:1609-1613.

35. Karatekin C, Ahluwalia R. Effects of adverse childhood experiences, stress, and social support on the health of college students. J Interpers Violence 2020;35:150-172.

36. Keller A, Litzelman K, Wisk LE, et al. Does the perception that stress affects health matter? The association with health and mortality. Health Psychol 2012;31:677.

37. Cohen S, Janicki-Deverts D, Miller GE. Psychological stress and disease. JAMA 2007;298:1685-1687.

38. Tenk J, Mátrai P, Hegyi P, et al. Perceived stress correlates with visceral obesity and lipid parameters of the metabolic syndrome: A systematic review and meta-analysis. Psychoneuroendocrinology 2018;95:63-73.

39. Macy RJ, Jones E, Graham LM, Roach L. Yoga for trauma and related mental health problems: A meta-review with clinical and service recommendations. Trauma Violence Abuse 2018;19:35-57.

40. Maroik S, Hazari CS, Mondal BC. Effect of yoga on health. Int J Yoga Physiother Phys Educ 2017;2:75-77.

41. McCall MC, Ward A, Roberts NW, Heneghan C. Overview of systematic reviews: Yoga as a therapeutic intervention for adults with acute and chronic health conditions. Evid Based Complement Alternat Med 2013;945895.

42. Jeter PE, Slutsky J, Singh N, Khalsa SBS. Yoga as a therapeutic intervention: A bibliometric analysis of published research studies from 1967 to 2013. J Altern Complement Med 2015;21:586-592.

43. Telles S, Singh N, Balkrishna A. Managing mental health disorders resulting from trauma through yoga: A review. Depress Res Treat 2012;401513. 
44. Lilly M, Hedlund J. Healing childhood sexual abuse with yoga. Int J Yoga Ther 2010;20:120-130.

45. Föhr T, Tolvanen A, Myllymäki T, et al. Subjective stress, objective heart rate variability-based stress, and recovery on workdays among overweight and psychologically distressed individuals: A cross-sectional study. J Occup Med Toxicol 2015;10:39.

46. Stalder T, Steudte-Schmiedgen S, Alexander N, et al. Stressrelated and basic determinants of hair cortisol in humans: A meta-analysis. Psychoneuroendocrinology 2017;77:261-274.

47. Emerson D, Hopper E. Overcoming Trauma Through Yoga: Reclaiming Your Body. Berkeley, CA, USA, North Atlantic Books, 2012.

48. Emerson D. Trauma-Sensitive Yoga in Therapy: Bringing the Body into Treatment. New York, NY, USA, WW Norton \& Company, 2015.

49. Felitti VJ, Anda RF, Nordenberg D, et al. Relationship of childhood abuse and household dysfunction to many of the leading causes of death in adults. The Adverse Childhood Experiences (ACE) study. Am J Prev Med 1998;14:245-258.

50. Dube SR, Felitti VJ, Dong M, et al. Childhood abuse, neglect, and household dysfunction and the risk of illicit drug use: The Adverse Childhood Experiences study. Pediatrics 2003;111:564-572.

51. Mason S, Santaularia N, Berge J, et al. Is the childhood home food environment a confounder of the association between child maltreatment exposure and adult body mass index? Prev Med 2018;110:86-92.

52. Schnurr PP, Spiro A, Vielhauer MJ, et al. Trauma in the lives of older men: Findings from the Normative Aging Study. J Clin Geropsychol 2002;8:175-187.

53. Ackard DM, Eisenberg ME, Neumark-Sztainer D. Longterm impact of adolescent dating violence on the behavioral and psychological health of male and female youth. J Pediatr 2007;151:476-481.

54. Jackson S, Beeken R, Wardle J. Obesity, perceived weight discrimination, and psychological well-being in older adults in England. Obesity 2015;23:1105-1111.
55. Vinokur A. Measures of economic deprivation/pressure. Online document at: http://sitemaker.umich.edu/avinokur/ measures, Last viewed January 31, 2020.

56. Vinokur A, Caplan R, Williams C. Effects of recent and past stresses on mental health: Coping with unemployment among Vietnam veterans and nonveterans. J Appl Soc Psychol 1987; 17:710-730.

57. Price RH, Choi JN, Vinokur AD. Links in the chain of adversity following job loss: How financial strain and loss of personal control lead to depression, impaired functioning, and poor health. J Occup Health Psychol 2002;7: 302.

58. Vinokur AD, Schul Y. The web of coping resources and pathways to reemployment following a job loss. J Occup Health Psychol 2002;7:68.

59. Nelson M, Lust K, Story M, Ehlinger E. Credit card debt, stress and key health risk behaviors among college students. Am J Health Promot 2008;22:400-407.

60. Sherwood NE, Wall M, Neumark-Sztainer D, Story M. Effect of socioeconomic status on weight change patterns in adolescents. Prev Chronic Dis 2009;6:A19.

61. Neumark-Sztainer D, Story M, Hannan PJ, Croll J. Overweight status and eating patterns among adolescents: Where do youths stand in comparison with the Healthy People 2010 objectives? Am J Public Health 2002;92:844-851.

Address correspondence to: Dianne Neumark-Sztainer, PhD, MPH, RD Division of Epidemiology and Community Health School of Public Health University of Minnesota

1300 South 2nd Street, Suite 300 Minneapolis, MN 55455

USA

E-mail: neumark@epi.umn.edu 